\title{
PAC1 Deficiency in a Murine Model Induces Gastric Mucosa Hypertrophy and Higher Basal Gastric Acid Output
}

\author{
Yuxin Lu • Patrizia Germano • Gordon V. Ohning • \\ John P. Vu • Joseph R. Pisegna
}

Received: 25 June 2010 / Accepted: 10 August 2010/Published online: 4 September 2010

(C) The Author(s) 2010. This article is published with open access at Springerlink.com

\begin{abstract}
Pituitary adenylate cyclase-activating polypeptide (PACAP) has been shown to increase the histamine release from gastric enterochromaffin-like (ECL) cells and promote gastric acid secretion in rats. In contrast, in mice, PACAP has been demonstrated to induce a decrease of gastric acid secretion, an effect presumably due to somatostatin release. To more clearly define the role of PACAP in the regulation of gastric acid output, a knockout mouse model for the PACAP-specific receptor PAC1 was applied in this study. Measurements of the basal and stimulated gastric acid secretion and morphological studies on the gastric mucosa were performed in both wild-type and PAC1-deficient mice. Compared with the wild-type mice, the PAC1-deficient mice showed a nearly threefold higher basal gastric acid output, increased gastric mucosa thickness and glands height, and proportional increases in parietal and total cell counts in the gastric mucosa. The PAC1-deficient mice also showed a trend of increased plasma gastrin levels and gastrin gene expression in the gastric mucosa. This study indicates that the expression of PAC1 is clearly important for maintaining the homeostasis of gastric acid secretion. Loss of PACAP receptor during development may lead to a compensatory mechanism regulating gastric acid secretion.
\end{abstract}

\footnotetext{
Y. Lu • P. Germano · G. V. Ohning · J. P. Vu • J. R. Pisegna $(\bowtie)$ Division of Gastroenterology and Hepatology,

Veterans Administration Greater Los Angeles Healthcare System, 11301 Wilshire Boulevard,

Los Angeles, CA 90073, USA

e-mail: jpisegna@ucla.edu

Y. Lu • P. Germano • G. V. Ohning $\cdot$ J. P. Vu • J. R. Pisegna Department of Medicine, David Geffen School of Medicine, University of California at Los Angeles,

Los Angeles, CA 90095, USA
}

Keywords PACAP·PAC1 deficient - Gastric acid secretion

\section{Introduction}

Pituitary adenylate cyclase-activating polypeptide (PACAP) belongs to the family of peptides that includes vasoactive intestinal polypeptide (VIP), secretin, and glucagon (Miyata et al. 1989). PACAP functions through its type 1 receptor (PAC1) and two VIP receptors, VPAC1and VPAC2. However, the PAC1 receptor is PACAP-specific, exhibiting 1,000-fold greater affinity for PACAP than for VIP (Fradinger et al. 2005). PACAP and PAC1 immunoreactivities show a similar distribution pattern in the gastrointestinal tract, mainly in the myenteric ganglia and the nerve fibers in muscle layers (Sundler et al. 1992; Miampamba et al. 2002). While PACAP has also been shown in the gastrointestinal mucosa (Miampamba et al. 2002), PAC1 has been reported to be expressed on isolated gastric enterochromaffin-like (ECL) cells (Oh et al. 2005). All these suggest that PACAP plays an important role in the regulation of gastric acid secretion and gastrointestinal motor function.

We and other authors have described that exogenously administered PACAP stimulates gastric acid secretion in rats (Zeng et al. 1998, 1999; Sandvik et al. 2001). The activation of PAC1 and its induction of ECL histamine release, in addition to the subsequent downstream parietal cell functioning, have been examined in vitro (Zeng et al. 1999). Histamine exocytosis in ECL cells is induced by extracellular $\mathrm{Ca}^{2+}$ entry into the ECL cell, rather than $\mathrm{IP}_{3}$ induced mobilization of intracellular $\mathrm{Ca}^{2+}$ (Lindström et al. 2001). Furthermore, PACAP-induced histamine secretion can be blocked by nifedipine, leading investigators to propose that the binding of PACAP to PAC1 regulates 
histamine secretion via the activation of receptor-operated $\mathrm{Ca}^{2+}$ channels by the induced secondary messenger cAMP in ECL cells (Lindström et al. 2001).

However, in murine models, the opposite effect has been shown, with PACAP inducing a reduction of gastric acid secretion, that it is presumed to be secondary to PACAPmediated somatostatin release through another PACAP receptor, VPAC1, on gastric D cells. This effect can be unmasked by immunoneutralization of somatostatin or in the presence of a SSTR2 antagonist in wild-type mice or in a SSTR2 gene knockout mouse model (Piqueras et al. 2004). The precise role of PACAP and its receptors in the regulation of gastric acid secretion has yet to be better defined. A PAC1-deficient mouse model is currently available (Jamen et al. 2000), and here, we have performed physiological and morphological studies on this mouse model to elucidate the in vivo effects of PAC1 deficiency on the gastric acid secretion.

\section{Materials and Methods}

\section{Animals}

Mice deficient in PAC1 receptor were generated as previously described (Jamen et al. 2000). The mice were received as F1 and further backcrossed on the C57BL/6 background for ten generations. Adult male mice aged 12-24 weeks were used in experimentation, and the wild-type (C57BL/6) counterparts served as controls to the PAC1-deficient mice. Mice were fasted for food for 16-18 $\mathrm{h}$ until the beginning of the experiments. All the procedures involving animals were conducted in accordance with international standards on animal welfare and approved by the Animal Research Committee of the Veterans Affairs Greater Los Angeles Healthcare System.

\section{Assay for Gastric Acid Secretion}

The assay was performed in urethane-anesthetized mice, as previously described (Zeng et al. 1998). Fasted wildtype and PAC1-deficient mice aged 12-24 weeks were anesthetized with urethane $(1.25 \mathrm{~g} / \mathrm{kg}$ i.p.). The abdomen was opened and the pylorus was ligated by 3-0 silk sutures (Ethicon, Somerville, NJ). A small incision was made in the foregut, and a double-lumen gastric cannula was inserted into the gastric lumen. The incision was then closed on the cannula by 3-0 silk sutures. A catheter [30-gauge needle inserted into polyethylene E-10 tubing (Baxter, Irvine, CA)] was placed into the saphenous vein for constant intravenous infusion of normal saline and administration of test substances $(0.1 \mathrm{ml} / \mathrm{h})$. Gastric acid secretion was determined by continuous intragastric perfusion with warm saline ( $\mathrm{pH} 7.0,0.3 \mathrm{ml} / \mathrm{min})$. Harvard syringe pumps (Harvard Apparatus, Holliston, MA) were applied for the above intravenous infusion and gastric perfusion. A 30-min period was allowed for stabilization and, thereafter, the effluents were collected at 10-min intervals and back titrated to $\mathrm{pH} 7.0(0.001 \mathrm{~N} \mathrm{NaOH})$ with an automatic titrator (Radiometer Copenhagen, Westlake, $\mathrm{OH}$ ). Rat gastrin I (Bachem, Torrance, CA) and histamine (SigmaAldrich, St Louis, MO) were dissolved in sterile water and administered at the indicated time points and doses in each experiment.

\section{Measurement of Plasma Gastrin Levels}

Plasma was obtained from wild-type and PAC1-deficient mice aged 12-24 weeks, and the circulating gastrin levels were determined by radioimmunoassay (RIA) using a commercial Euria-Gastrin kit (Euro Diagnostica, Maelmo, Sweden; courtesy of Dr. Stephen Wank, NIDDK and NIH).

\section{Assay for Marker Gene Expression in Gastric Mucosa}

qPCR was performed to determine the expression level of marker genes in mouse gastric mucosa, as previously described (Lambrecht et al. 2005). Freshly resected stomachs from fasted mice aged 16 weeks were opened, and the oxyntic mucosa was scraped off using the sharp edge of a slide. The fragments were homogenized in $2 \mathrm{ml}$ of RNAlater (Qiagen, Valencia, CA) on ice and then filtered through a nylon sieve. Total RNA from the homogenate was isolated using the RNeasy protect mini kit (Qiagen), and $0.5 \mu \mathrm{g}$ of total RNA was applied for the reverse transcriptase (RT) reaction using the Superscript first-strand synthesis kit (Invitrogen, Carlsbad, CA). Two micrograms of RT product was then added in a reaction with SYBR premix Taq (Takara Bio, Shiga, Japan) for qPCR, which was performed on the DNA Engine Opticon 2 system (MJ Research, Waltham, MA). The cycle of threshold, C(T), was determined as the fluorescent signal of 1 standard deviation over background. The efficiency of each primer pair was measured by amplification of the known amount of cDNA starting material $(10 \mathrm{pg}-10 \mathrm{ng})$. Target primer pair amplifications were compared with the reference primer pair (beta-actin) amplification in the same experiment for each RT product tested. All reactions were carried out in duplicate. The relative expression ratio of the target gene compared with the reference gene was calculated according to the Pfaffl's formula:

$$
\begin{aligned}
\text { Ratio }= & \left(\text { Efficiency }_{\text {target }}\right)^{\Delta \mathrm{C}(\mathrm{T}) \text { target }(\text { sample-control })} \\
& /\left(\text { Efficiency }_{\text {reference }}\right)^{\Delta \mathrm{C}(\mathrm{T}) \text { reference (sample-control })} .
\end{aligned}
$$


The sequences of primer pairs for the marker genes in mouse gastric mucosa are listed as follows:

VMAT-2: S-CTCGCGCTGCTGCTAGACAACAT; AS-GGCGATCAGCAGGAAGGCATAGC

HDC: S-CTTTCTCATCCCGGCTACTATCCA; ASACCGCGTTGTCTTCCTCCTGT

Somatostatin: S-GTCCTGGCTTTGGGCGGTGTC; AS-GAGATATGGGGTTTGGGGGAGAGG

Pepsinogen: S-TCCGGATTTCTTGCCTATGACACT; AS-ACTGGCTGGCACTGGGTAGGTAAC

Na-K-ATPase: S-CGCCCTCACACCCCCTCCC ACTAC; AS-CCACCAGATCCCCGACGACGACAT

Kenq1: S-GCCCGGCCCACACTAACTGC; AS-GG TGCCCAAGCCCAAGGAAC

H-K-ATPase: S-GACCGGACGTGTATGGGGAAA GAG; AS-GGGTTGCTGTAGTGGGGCTGTGCT

Gastrin: S-GGGAGCGCCACAACAGC; AS-GCGG CGGCCAAAGTCCA

CCK-B receptor: S-CGCCGCGGGAGCAGGTG; ASATGGCCGCGAGATTTAGAGTGGAC

Somatostatin receptor-2: S-CGACCCCGGACAGCCA AGATGAT; AS-ATGGCCACAGACACGGAA GAGACG

Beta-actin: S-CTAAGGCCAACCGTGAAAAGA TGA; AS-ACCGCTCGTTGCCAATAGTGATG

Immunohistochemistry and Morphological Measurements

Stomachs were collected from fasted wild-type and PAC1deficient male mice aged 12-16 weeks. Tissues were fixed overnight in $4 \%$ paraformaldehyde, embedded in paraffin, and 5- $\mu \mathrm{m}$ sections were stained with hematoxylin and eosin (H\&E) or mouse monoclonal H-K-ATPase antibodies 1:500 (gift of Dr. George Sachs, UCLA), rabbit polyclonal chromogranin A antibodies 1:2,000 (Incstar, Stillwater, $\mathrm{MN}$ ) or mouse monoclonal somatostatin antibodies 1:100 (CURE Antibody Core, Los Angeles). Immunohistochemistry was performed using a peroxidase method. Rehydrated tissue sections were incubated for $18 \mathrm{~h}$ at $4^{\circ} \mathrm{C}$ with the respective primary antibodies, then washed and incubated for $1 \mathrm{~h}$ at room temperature with biotinylated goat antirabbit or antimouse antibodies 1:500 (Vector Laboratories, Burlingame, CA), incubated $1 \mathrm{~h}$ at room temperature with avidin-biotinylated horseradish peroxidase complex (Vectastain ABC Elite Kit, Vector Laboratories),

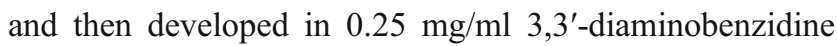
tetrahydrochloride (DAB). After washing, sections were counterstained with hematoxylin.

Sections were viewed and photographed under microscope with the $\times 10$ objective. Sections stained with H\&E were used to measure the mucosal thickness, gland height, and pit height. Six to ten separate measurements were made per animal. Sections stained with H-K-ATPase antibody were used to count the parietal cells (stained) and total cells per gland. Cells of six to ten well-oriented glands per animal were counted manually. Chromogranin A-positive cells and somatostatin-positive cells were counted per millimeter of horizontal length of tissue, using five to eight separate fields per animal with total length of $3-8 \mathrm{~mm}$ per animal.

\section{Statistical Analysis}

Group comparisons were analyzed by using the Student's $t$ test. Statistical significance was set at $p<0.05$.

\section{Results}

PAC1 Deficiency Results in Basal Gastric Acid Hypersecretion

Since PAC1 is the specific receptor for PACAP and the only receptor expressed on ECL cells in gastric mucosa, we were interested in understanding the effects of PAC1 deficiency on the basal gastric acid secretion. After an overnight fast, mice were anesthetized to perform gastric acid secretion assay with constant intravenous infusion of saline. PAC1-deficient mice were noted to have an elevated basal gastric acid output over the entire observation period of $110 \mathrm{~min}$ (Fig. 1). The average basal gastric acid output observed in PAC1 knockout mice was $0.29 \pm 0.05 \mu \mathrm{mol} / 10 \mathrm{~min}$, whereas for the wild-type mice, the average basal acid output was $0.10 \pm 0.01 \mu \mathrm{mol} /$ $10 \mathrm{~min}$. This translated to an approximately threefold higher basal stimulation in PAC1-deficient mice, compared with wild-type mice $(p<0.001)$.

To further understand the profile of gastric acid secretion in PAC1-deficient mice, we next investigated the histamine stimulatory pathway (Fig. 2). After 30 min of stabilization with warm saline, the mice were constantly infused with histamine at the dosage of $1 \mathrm{mg} / \mathrm{kg} / \mathrm{h}$. The resulting gastric

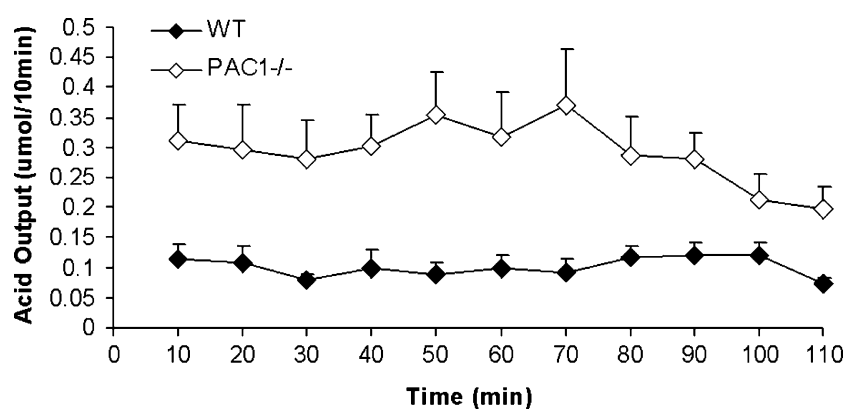

Figure 1 Measurements of basal gastric acid output in PAC1deficient and wild-type mice fasted overnight, anesthetized, and constantly infused with warm saline. Data shown are the average values \pm standard error of the mean (SEM; $n=5$ mice per group) 


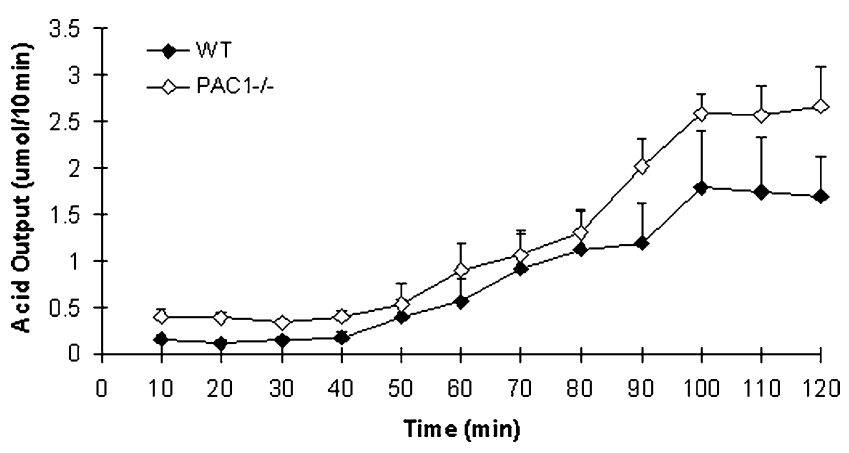

Figure 2 Measurements of histamine-stimulated gastric acid output in PAC1-deficient and wild-type mice. Histamine was infused $30 \mathrm{~min}$ post-stabilization with saline. Data shown are the average values \pm SEM ( $n=3$ mice per group)

acid output increased significantly as early as 20 min posthistamine infusion in both PAC1-deficient and wild-type mice and reached the peak at the end of the 2-h observation period, sevenfold in PAC1-deficient mice and tenfold in wild-type mice, compared with their basal acid output. Compared with the wild-type mice, the PAC1-deficient mice had higher acid secretion levels at the end of the observation period $(p<0.01)$. The results indicate that the PAC1-deficient mice have an intact histamine stimulatory pathway in gastric acid secretion.

The gastrin stimulatory pathway was also explored with exogenous gastrin administration in both PAC1-deficient and wild-type mice (Fig. 3). After $30 \mathrm{~min}$ of stabilization, the mice were constantly infused with rat gastrin I peptide. At the dosage of $100 \mu \mathrm{g} / \mathrm{kg} / \mathrm{h}$, the acid output was increased twofold in the wild-type mice, while no stimulatory effect was shown in the PAC1-deficient mice. However, at a higher dosage of $500 \mu \mathrm{g} / \mathrm{kg} / \mathrm{h}$ of rat gastrin I peptide in both PAC1-deficient and wild-type mice, the gastric acid output was increased to a significant level $(p<0.05)$, which was 2.3-fold in PAC1-deficient mice and sevenfold in wild-type mice, compared with their basal acid output. These results indicate that, although in the PAC1-deficient mice the gastrin stimulatory pathway is functional, there is a higher threshold to the effects of exogenous gastrin.

\section{PAC1 Deficiency Results in Hypertrophic Gastric Mucosa}

To determine whether differences in tissue histology could explain the physiological responses described above, stomach tissues from fasted PAC1-deficient and wild-type mice were sectioned for H\&E staining (Fig. 4a). PAC1deficient mice showed a greater mucosal thickness $(0.49 \pm$ $0.12 \mathrm{~mm})$ compared with wild-type mice $(0.33 \pm 0.06 \mathrm{~mm}$, $p<0.01$; Fig. 4b). This different mucosal thickness in the two groups of mice was ascribed to the greater gland height in PAC1-deficient mice $(0.43 \pm 0.12 \mathrm{~mm})$ compared with wildtype mice $(0.27 \pm 0.06 \mathrm{~mm}, p<0.01$; Fig. $4 \mathrm{c})$. No significant difference was found between the two groups of mice with regards to the pit height (Fig. 4d).

To assess the effects of PAC1 deficiency on the cellular components of the gastric glands, we performed immunohistochemical staining using anti-H-K-ATPase antibodies. The stained sections (in Fig. 5a) showed an increased number of parietal cells per gland in PAC1-deficient mice (27.5 \pm 8.4$)$ compared with wild-type mice $(16.1 \pm 3.4, p<$ 0.01; Fig. 5b). The total cellular composition (Fig. $5 \mathrm{c}$ ) per gland in PAC1-deficient mice $(56.9 \pm 13.6)$ was also increased, compared with the wild-type mice gland (32.8 \pm 7.3 , $p<0.01)$. These results indicate that the parietal cells mass is increased in the gastric mucosa of PAC1-deficient mice.

PAC1-Deficient Mice Show a Trend of Increase in Plasma Gastrin Level and Gastrin Gene Expression

To determine whether there is a difference in the circulating gastrin levels between PAC1-deficient and wild-type mice, fasting plasma gastrin levels were measured by RIA (Fig. 6). PAC1-deficient mice had an average circulating gastrin level of $115 \pm 50 \mathrm{pmol} / \mathrm{L}$, while wild-type mice had an average level of $76 \pm 35 \mathrm{pmol} / \mathrm{L}$, indicating that PAC1deficient mice have $34 \%$ higher circulating gastrin levels, compared with the wild-type mice $(p=0.035$ ). The observed higher threshold to the effects of exogenous gastrin in PAC1-deficient mice might result from the relatively higher levels of endogenous gastrin observed in this model.

In order to correlate the above findings, qPCR was performed to measure the expression of specific cell type marker genes (gastrin, somatostatin, somatostatin receptor 2, histidine decarboxylase, vesicular monoamine transporter 2, cholecystokinin beta receptor, H-K-ATPase, Kcnq1, pepsinogen, ghrelin, and Na-K-ATPase in gastric mucosa). The results (in Fig. 7) show a gastrin mRNA level in the gastric mucosa approximately fivefold higher in PAC1deficient mice compared with wild-type mice $(p=0.01)$. A lower change in gene expression (ratio $<2$ ) was found in the

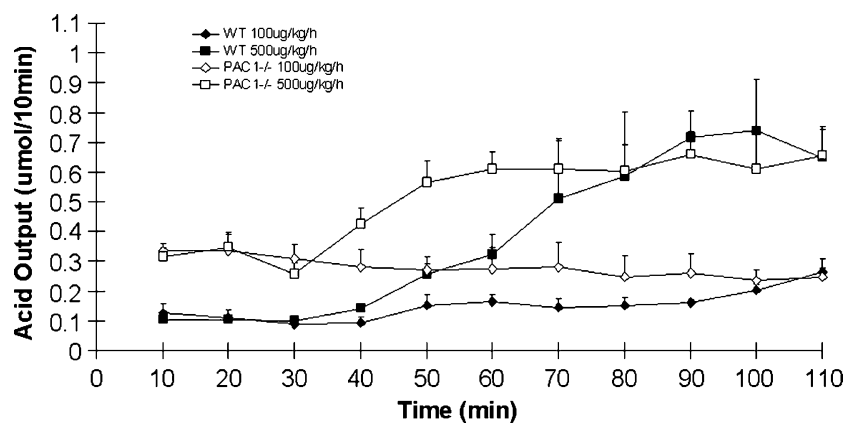

Figure 3 Measurements of gastrin-stimulated gastric acid output in PAC1-deficient and wild-type mice. Rat gastrin I was infused $30 \mathrm{~min}$ post-stabilization with saline. Data shown are the average values \pm SEM ( $n=4$ mice per group) 
Figure 4 H\&E staining and morphological measurements of gastric mucosa in PAC1deficient and wild-type mice. a H\&E staining, b mucosa thickness $(p<0.01)$, c gland height $(p<0.01)$, d pit height. Data shown are the average values \pm SEM $(n=3$ mice per group)
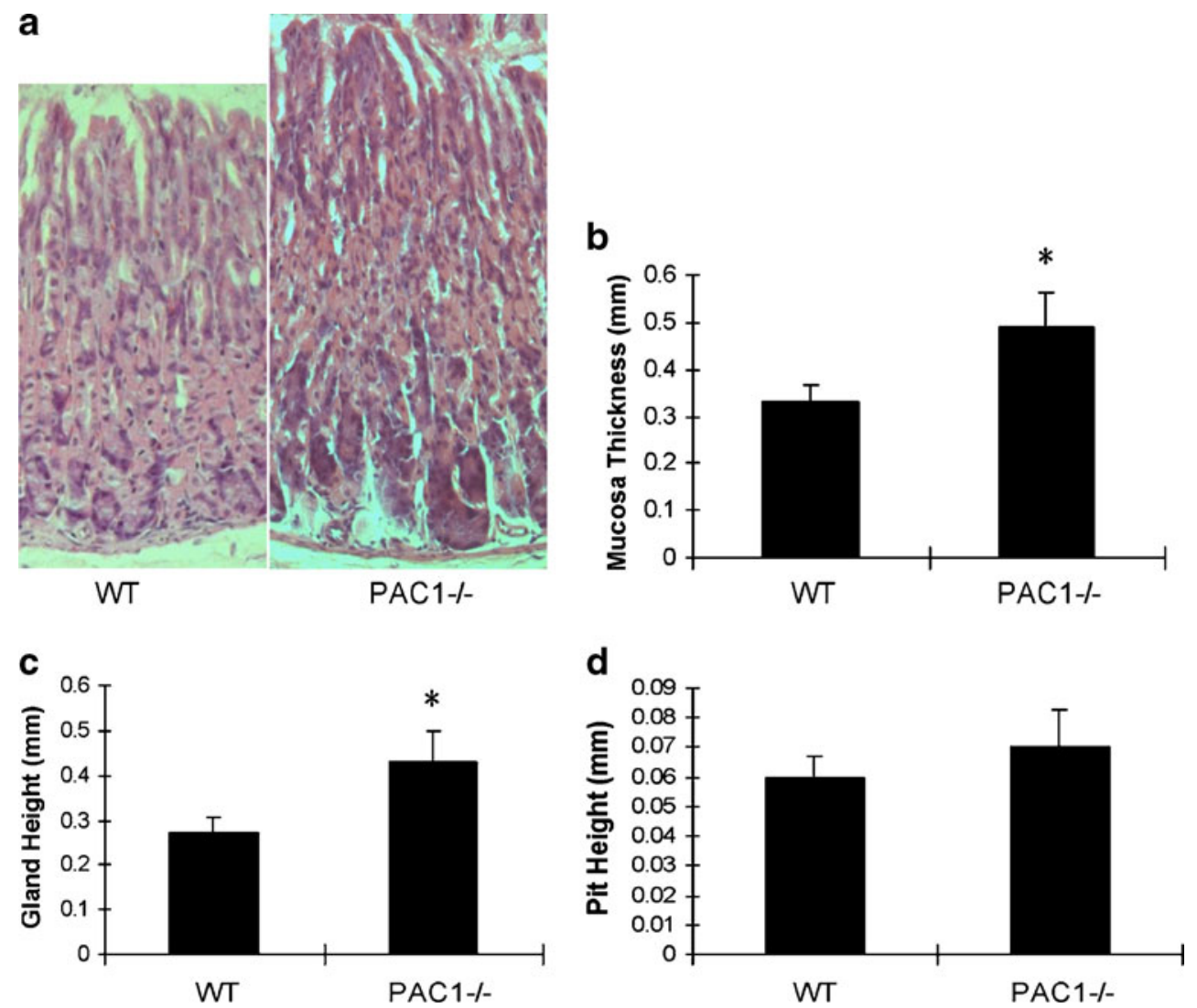

PAC1-deficient mice for the markers of other cell types, such as ECL, D, and X/A cells, as shown in Fig. 7. No variation was found in the expression of the beta-actin gene in gastric mucosa between wild-type and PAC1-deficient mice (data not shown).

\section{PAC1 Deficiency Does Not Result in Change in D Cell Counts}

To determine whether a difference in the numbers of $\mathrm{D}$ cells and other neuroendocrine cells exists between PAC1deficient and wild-type mice, to account for the noted physiological changes, immunohistochemical analysis with antisomatostatin (D cells) and antichromogranin A (neuroendocrine cells) antibodies was performed on gastric corpus sections. A similar numbers of D cells (Fig. 8a, b) were found in PAC1-deficient $(13.6 \pm 6.2 / \mathrm{mm})$ and wild-type mice $(14.7 \pm 9.2 / \mathrm{mm}, p>0.05)$, as well as total neuroendocrine cells numbers (Fig. 8c, d) in PAC1-deficient $(36.3 \pm$ $23.2 / \mathrm{mm})$ and wild-type mice $(45.1 \pm 22.7 / \mathrm{mm}, p>0.05)$. These results are consistent with the qPCR data previously shown in this paper.

\section{Discussion}

Historically, studies describing the effects of exogenous PACAP administration on gastric acid secretion have given very different and opposite results (Zeng et al. 1999; Sandvik et al. 2001; Piqueras et al. 2004). These different data are due in part to the ability of PACAP to bind to both PAC1 and VPACs receptors, which may be species-related. The precise role of PACAP in mediating gastric acid output has yet to be completely determined. The data shown here characterize, for the first time, the effects of PAC1 deletion on gastric acid physiology and gastric histology. In the PAC1deficient mouse model, we explored the consequence of the effects of gastrin and histamine on gastric acid physiology. Gastrin is considered upstream of the effect because it is generally released by the antral $G$ cells in response to a protein diet through a yet unknown receptor. Antral $G$ cell stimulation results in gastrin release. Gastrin in turn stimulates the CCK2 receptor present on the ECL cell of the stomach to in turn release histamine. The mechanism regulating this process is an intracellular $\mathrm{Ca}++$ pathway (Zeng et al. 1999). The elevated basal gastric acid output, observed in the PAC1deficient mice, most likely results from a downward shift in the neuroendocrine axis that regulates acid output, leading to enhanced parietal cell number and function. The PAC1deficient mice in this study had an increased mucosal thickness and gland height, due in part to increased parietal cell number, compared with the wild-type mice.

In the PAC1-deficient mice, the observed hypertrophy of the gastric mucosa could be partially due to the relatively higher gastrin levels observed. Gastrin is an important 
Figure 5 Immunohistochemistry and measurements of gastric gland cell components in PAC1deficient and wild-type mice. a Immunohistochemical staining with anti-H-K-ATPase antibody, b parietal cell counts $(p<0.01)$, c total gland cell counts $(p<0.01)$. Data shown are the average values $\pm \operatorname{SEM}(n=3$ mice per group) a

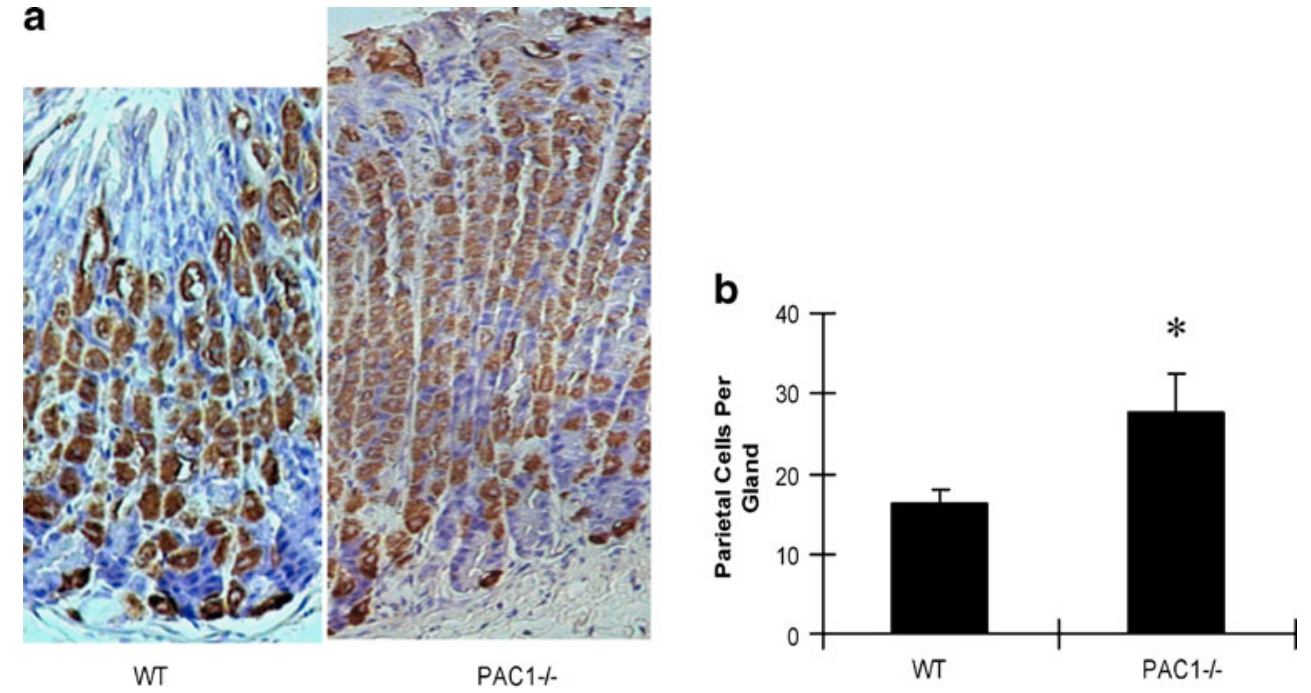

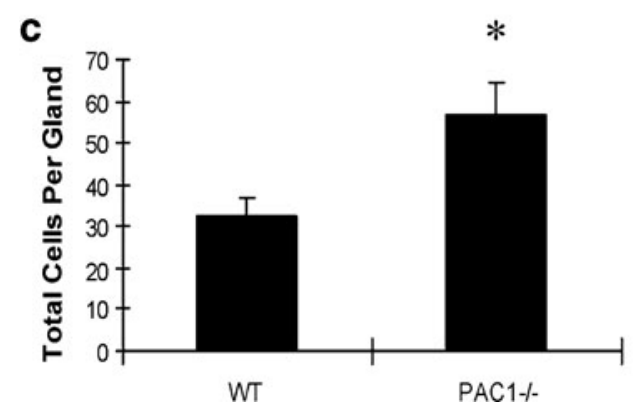

hormone in the differentiation of the stomach oxyntic mucosal cells. In a gastrin-deficient mouse model, decreased numbers of parietal and ECL cells were observed (Koh et al. 1997). Since the advent of potent gastric acid inhibitory agents, such as the proton pump inhibitors, that block the activity of $\mathrm{H}-\mathrm{K}$-ATPase, there has been a concern regarding their potential risk for inducing ECL cell hyperplasia and gastric carcinoid tumor genesis. The induction of these tumors is thought to be due to hypergastrinemia caused by proton pump inhibitors. In our PAC1-deficient mice, we did not identify the development of gastric carcinoid tumors or ECLomas (Lieu et al. 2006).

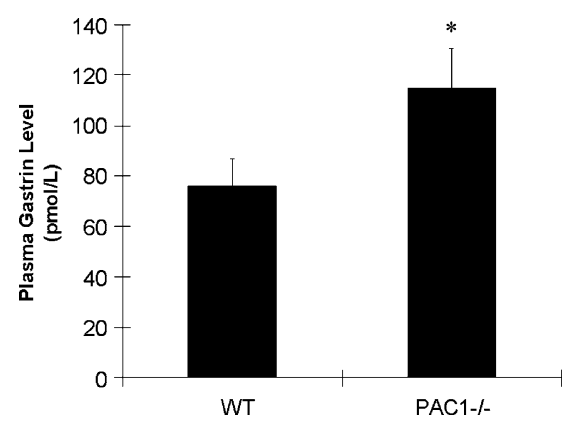

Figure 6 Levels of fasting plasma gastrin were measured in PAC1deficient $(p=0.035)$ and wild-type mice by RIA. Data shown are the average values $\pm \operatorname{SEM}(n=10$ mice per group)
PACAP has demonstrated antisecretory effects through the release of somatostatin from D cells in a mouse model; however, a rapid change in the concentration of histamine or gastric acid induced by stimulants usually works as a trigger for somatostatin release (Piqueras et al. 2004). In PAC1-deficient mice, basal gastric acid output has been rebalanced to a new stable level, a situation in which the physiological status of D cells may not be altered. This is consistent with the lack of any significant difference found in this study in D cell counts and in somatostatin and somatostatin receptor 2 gene expression in the gastric mucosa of both PAC1-deficient and wild-type mice.

PACAP has been shown to stimulate the proliferation of ECL cells (Läuffer et al. 1999). We previously demonstrated by cytofluorimetric analysis and RT-PCR that only PAC1, but not VPAC1, is expressed on ECL cells (Oh et al. 2005), leading to the conclusion that the $\mathrm{PAC} 1$ receptor is the sole pathway for PACAP signaling in these cells. We would, therefore, expect that the absence of PACAP stimulation in PAC1-deficient mice could have a significant effect on ECL cell differentiation. However, the levels of expression of the ECL-specific HDC and VMAT2 genes in the gastric mucosa were similar in both PAC1-deficient and wildtype mice. In addition, no difference was seen between the two groups of mice in the number of chromogranin Apositive cells, of which the ECL cells constitute the larger 
Figure 7 Marker genes expression of gastrin, somatostatin, somatostatin receptor 2 (SSTR2), histidine decarboxylase, vesicular monoamine transporter 2 (VMAT2), cholecystokinin beta receptor (CCKBR), H-KATPase, Kcnq1, pepsinogen, ghrelin, and $\mathrm{Na}$-K-ATPase were analyzed by qPCR in PAC1deficient and wild-type mice gastric mucosa. Data shown are the average values \pm SEM ( $n=4$ mice per group). Statistical analysis was performed using Student's $t$ test (paired samples). Error bars represent the SEM

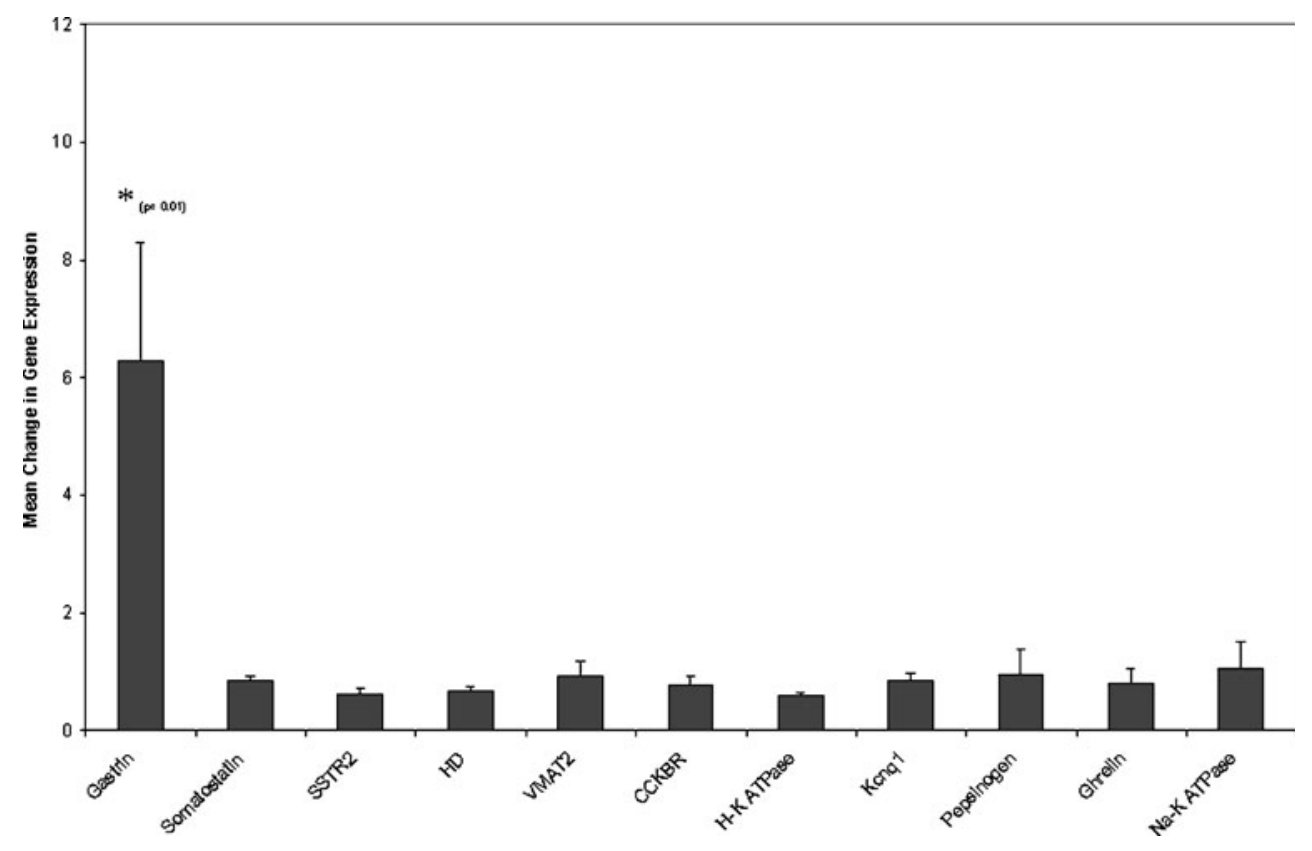

quote. Since gastrin also has a stimulatory effect on ECL cells, this phenomenon might be due to the relative increase of gastrin level in PAC1-deficient mice that could compensate for the lack of PACAP (McLaughlin et al. 2004). Direct staining of antral G cells, staining of ECL cells with
anti-HDC and anti-VMAT2 antibodies, as well as studies on the isolated G and ECL cell population, which we are working on, will further increase our understanding of the physiological changes in G and ECL cells due to PAC1 deficiency.
Figure 8 Immunohistochemistry and neuroendocrine cell counts in PAC1-deficient and wild-type mice. a Immunohistochemical staining with antisomatostatin antibody, b D cell counts, c immunohistochemical staining with antichromogranin A antibody, $\mathbf{d}$ chromogranin A-positive cell counts. Data shown are the average values \pm SEM ( $n=3$ mice per group)

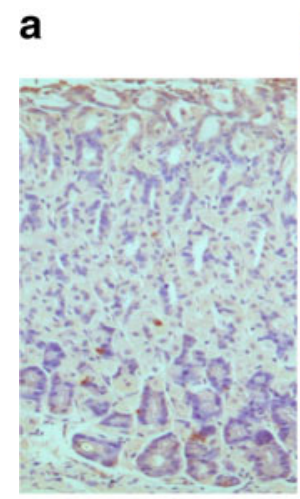

WT

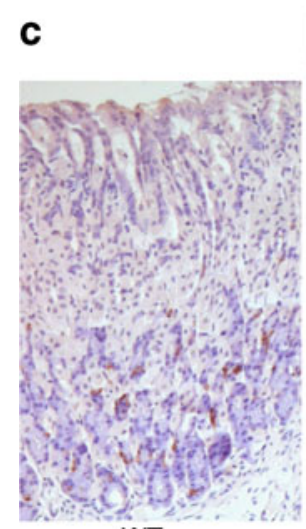

WT



PAC1-/-

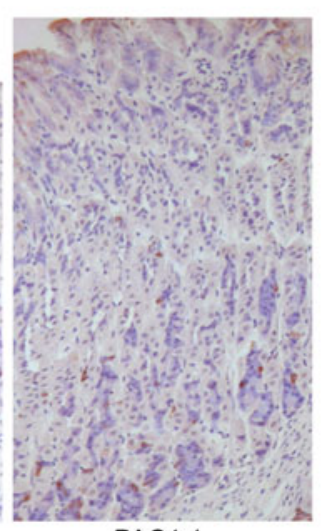

PAC1-/-

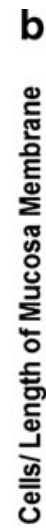

d

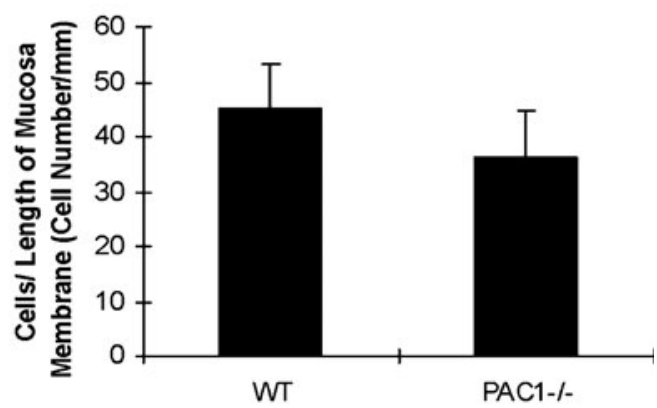


There was a concern about using urethane in this study. Urethane has been reported to inhibit acid secretion by a mechanism of stimulating somatostatin release, associated with a reduction in low basal acid secretion in rodent models. However, in our current study, despite this potential for reducing gastric acid secretion by urethane, we have observed, in the PAC1-deficient mice, a significant increase in gastric acid secretion, compared with wild-type mice with normal expression of PAC1. Under urethane anesthesia, PAC1-deficient mice showed intact responses to secretagogues. We considered other anesthetics such as isoflurane and halothane. However, isoflurane has been shown to have a stimulatory effect on acid secretion in rats (Kaunitz, unpublished observations). Halothane has been reported to increase the gastric pH in humans (Schurizek et al. 1989).

In our knockout mouse model, relatively increased gastrin levels may have contributed to elevated gastric acid output, by exerting a direct stimulatory effect on gastric parietal cells via gastrin receptor. In a previously described SSTR2 knockout mouse model, the observed morphological and functional changes signaled a shift in ECL cell regulation: from a paracrine (somatostatin)-dependent pathway to a possible hypothesized neurocrine-dependent pathway (Zhao et al. 2008). Here, we suggest a similar shift in the stimulatory regulation of the parietal cell by the gastrin-ECL cell axis with an enhancement of the direct gastrin effects. The rat gastrin I peptide used in our studies has been showed to be less potent than pentagastrin in the stimulation of gastric acid secretion as previously reported (Piqueras et al. 2004). We have already developed and studied VIP-deficient mice in which we have shown profound motility changes throughout their intestine (unpublished data), leading to the development of intestinal ileus and a form of Hirschsprung's disease (Lelievre et al. 2007). Characterization of the effects of VIP hormone deletion on the development of gastric acid secretion would be also very interesting to study. The specific role of PACAP hormone deficiency was not examined in our PAC1 receptor knockout mice. However, this model would be of significant importance to further our understanding of the direct role of the hormone PACAP in regulating gastric acid secretion. With the recent development by several groups of a $\mathrm{PACAP}^{-/-}$mice, this pathway can be later explored.

Taken as a whole, our findings suggest that there might be a remodeling of the neuroendocrine mechanisms that regulate gastric acid output in PAC1-deficient mice. Loss of a stimulatory pathway via PAC1 leads to physiological compensation and to an elevated basal acid output that is in part mediated by a release of gastrin or other unknown mechanisms.
Acknowledgements This work was supported by the Department of Veterans Affairs Merit Review Grant (JRP). Antibody \#S607 raised against somatostatin was provided by the CURE Digestive Diseases Research Center, Antibody/RIA Core, NIH Grant \#DK41301.

Open Access This article is distributed under the terms of the Creative Commons Attribution Noncommercial License which permits any noncommercial use, distribution, and reproduction in any medium, provided the original author(s) and source are credited.

\section{References}

Fradinger EA, Tello JA, Rivier JE, Sherwood NM (2005) Characterization of four receptor cDNAs: PAC1, VPAC1, a novel PAC1 and a partial GHRH in zebrafish. Mol Cell Endocrinol 231(1-2): 49-63

Jamen F, Persson K, Bertrand G et al (2000) PAC1 receptordeficient mice display impaired insulinotropic response to glucose and reduced glucose tolerance. J Clin Invest 105 (9):1307-1315

Koh TJ, Goldenring JR, Ito S et al (1997) Gastrin deficiency results in altered gastric differentiation and decreased colonic proliferation in mice. Gastroenterology 113(3):1015-1025

Lambrecht NW, Yakubov I, Scott D, Sachs G (2005) Identification of the $\mathrm{K}$ efflux channel coupled to the gastric H-K-ATPase during acid secretion. Physiol Genomics 21(1):81-91

Läuffer JM, Modlin IM, Hinoue T et al (1999) Pituitary adenylate cyclase-activating polypeptide modulates gastric enterochromaffinlike cell proliferation in rats. Gastroenterology 116(3):623-635

Lelievre V, Favrais G, Abad C et al (2007) Gastrointestinal dysfunction in mice with a targeted mutation in the gene encoding vasoactive intestinal polypeptide: a model for the study of intestinal ileus and Hirschsprung's disease. Peptides 28 (9):1688-1699

Lieu SN, Oh DS, Pisegna JR, Germano PM (2006) Neuroendocrine tumors express PAC1 receptors. Ann NY Acad Sci 1070:399404

Lindström E, Eliasson L, Björkqvist M, Håkanson R (2001) Gastrin and the neuropeptide PACAP evoke secretion from rat stomach histamine-containing (ECL) cells by stimulating influx of $\mathrm{Ca} 2+$ through different Ca2+ channels. J Physiol 535(Pt 3):663-677

McLaughlin JT, Ai W, Sinclair NF et al (2004) PACAP and gastrin regulate the histidine decarboxylase promoter via distinct mechanisms. Am J Physiol Gastrointest Liver Physiol 286(1): G51-G59

Miampamba M, Germano PM, Arli S, Wong HH, Scott D, Taché Y, Pisegna JR (2002) Expression of pituitary adenylate cyclase-activating polypeptide and PACAP type 1 receptor in the rat gastric and colonic myenteric neurons. Regul Pept 105 (3): $145-154$

Miyata A, Arimura A, Dahl RR et al (1989) Isolation of a novel 38 residue-hypothalamic polypeptide which stimulates adenylate cyclase in pituitary cells. Biochem Biophys Res Commun 164 (1):567-574

Oh DS, Lieu SN, Yamaguchi DJ et al (2005) PACAP regulation of secretion and proliferation of pure populations of gastric ECL cells. J Mol Neurosci 26(1):85-97

Piqueras L, Taché Y, Martínez V (2004) Peripheral PACAP inhibits gastric acid secretion through somatostatin release in mice. Br J Pharmacol 142(1):67-78 
Sandvik AK, Cui G, Bakke I, Munkvold B, Waldum HL (2001) PACAP stimulates gastric acid secretion in the rat by inducing histamine release. Am J Physiol Gastrointest Liver Physiol 281(4):G997-G1003

Schurizek BA, Willacy LH, Kraglund K, Andreasen F, Juhl B (1989) Effects of general anaesthesia with enflurane on antroduodenal motility, $\mathrm{pH}$ and gastric emptying rate in man. Eur $\mathrm{J}$ Anaesthesiol 6(4):265-279

Sundler F, Ekblad E, Absood A, Håkanson R, Köves K, Arimura A (1992) Pituitary adenylate cyclase activating peptide: a novel vasoactive intestinal peptide-like neuropeptide in the gut. Neuroscience 46(2):439-454
Zeng N, Kang T, Lyu RM et al (1998) The pituitary adenylate cyclase activating polypeptide type 1 receptor (PAC1-R) is expressed on gastric ECL cells: evidence by immunocytochemistry and RTPCR. Ann NY Acad Sci 865:147-156

Zeng N, Athmann C, Kang T et al (1999) PACAP type I receptor activation regulates ECL cells and gastric acid secretion. J Clin Invest 104(10):1383-1391

Zhao CM, Martinez V, Piqueras L, Wang L, Taché Y, Chen D (2008) Control of gastric acid secretion in somatostatin receptor 2 deficient mice: shift from endocrine/paracrine to neurocrine pathways. Endocrinology 149(2):498-505 